\title{
The origin of lithogenic sediment in the south-western Ross Sea and implications for iron fertilization
}

\author{
V.H.L. WINTON ${ }^{1}$, G.B. DUNBAR ${ }^{2}$, C.B. ATKINS ${ }^{3}$, N.A.N. BERTLER ${ }^{2,4}$, B. DELMONTE ${ }^{5}$, P.S. ANDERSSON ${ }^{6}$ \\ A. BOWIE ${ }^{7,8}$ and R. EDWARDS ${ }^{1}$ \\ ${ }^{1}$ Physics and Astronomy, Curtin University, Perth, Western Australia, Australia \\ ${ }^{2}$ Antarctic Research Centre, Victoria University of Wellington, Wellington, New Zealand \\ ${ }^{3}$ School of Geography, Environment and Earth Sciences, Victoria University of Wellington, Wellington, New Zealand \\ ${ }^{4}$ GNS Science, National Isotope Centre, Lower Hutt, New Zealand \\ ${ }^{5}$ DISAT, Department of Earth and Environmental Sciences, University of Milano-Bicocca, Milano, Italy \\ ${ }^{6}$ Department of Geosciences, Swedish Museum of Natural History, Stockholm, Sweden \\ ${ }^{7}$ Antarctic Climate and Ecosystems CRC, University of Tasmania, Hobart, Tasmania, Australia \\ ${ }^{8}$ Institute for Antarctic and Southern Ocean Studies, University of Tasmania, Hobart, Tasmania, Australia \\ holly.winton@postgrad.curtin.edu.au
}

\begin{abstract}
Summer iron (Fe) fertilization in the Ross Sea has previously been observed in association with diatom productivity, lithogenic particles and excess Fe in the water column. This productivity event occurred during an early breakout of sea ice via katabatic winds, suggesting that aeolian dust could be an important source of lithogenic Fe required for diatom growth in the Ross Sea. Here we investigate the provenance of size-selected dust deposited on sea ice in McMurdo Sound, south-western (SW) Ross Sea. The isotopic signature of McMurdo Sound dust $\left(0.70533<{ }^{87} \mathrm{Sr} /{ }^{86} \mathrm{Sr}<0.70915\right.$ and $\left.-1.1<\varepsilon_{\mathrm{Nd}}(0)<3.45\right)$ confirms that dust is locally sourced from the McMurdo Sound debris bands and comprises a two-component mixture of McMurdo Volcanic Group and southern Victoria Land lithologies. In addition, the provenance of lithogenic sediment trapped in the water column was investigated, and the isotopic signature $\left(\varepsilon_{\mathrm{Nd}}(0)=3.9,{ }^{87} \mathrm{Sr} /{ }^{86} \mathrm{Sr}=0.70434\right)$ is differentiated from long-range transported dust originating from South America and Australia. Elevated lithogenic accumulation rates in deeper sediment traps in the Ross Sea suggest that sinking particles in the water column cannot simply result from dust input at the surface. This discrepancy can be best explained by significant upwelling and remobilization of lithogenic Fe from the sea floor.
\end{abstract}

Received 30 June 2015, accepted 17 January 2016, first published online 26 February 2016

Key words: Antarctica, dust, dust provenance, iron, McMurdo Sound

\section{Introduction}

Atmospheric dust is potentially an important source of dissolved iron (DFe) which is the limiting nutrient required for primary production in vast regions of the remote Southern Ocean, including Antarctica's marginal seas (Sedwick et al. 2000, Boyd et al. 2010). Despite being seasonally iron $(\mathrm{Fe})$ limited, the high-nutrient, highchlorophyll regime of the Ross Sea is the most biologically productive continental shelf region in Antarctica, and supports intense phytoplankton blooms in the summer (Arrigo et al. 2008). Although the flux of Fe into the Ross Sea plays a critical role in determining its productivity, the origin(s) of this $\mathrm{Fe}$ remains poorly constrained (Sedwick et al. 2011).

\section{Dust deposition in Antarctica}

Global 'background' dust is characterized by fine particles having a mass modal diameter $<5 \mu \mathrm{m}$, long atmospheric residence time and modern mass deposition rates in the order of $0.001-0.02 \mathrm{~g} \mathrm{~m}^{-2} \mathrm{yr}^{-1}$ in the Southern Ocean (Wagener et al. 2008 and references therein). The isolated, snow and ice-covered central East Antarctic Plateau (EAP) has proven to be an excellent location for investigating long-range transport of dust representative of the broader Southern Hemisphere, both at present and in the past (Delmonte et al. 2007, 2008). Moreover, the high EAP has much lower accumulation rates of $\sim 0.0002-0.0006 \mathrm{~g} \mathrm{~m}^{-2} \mathrm{yr}^{-1}$ during the Holocene (Albani et al. 2012). Recently, it has become apparent that peripheral areas of the Antarctic ice sheet, close to high elevation ice-free mountain ranges, such as the Transantarctic Mountains (TAM), can receive significant additional dust inputs from exposed Antarctic sources, some of which have been ice-free for millions of years (Delmonte et al. 2013 and references therein).

The relative contribution of much smaller, patchy but proximal dust sources to the atmospheric dust load over Antarctica and the Southern Ocean is not well known. 


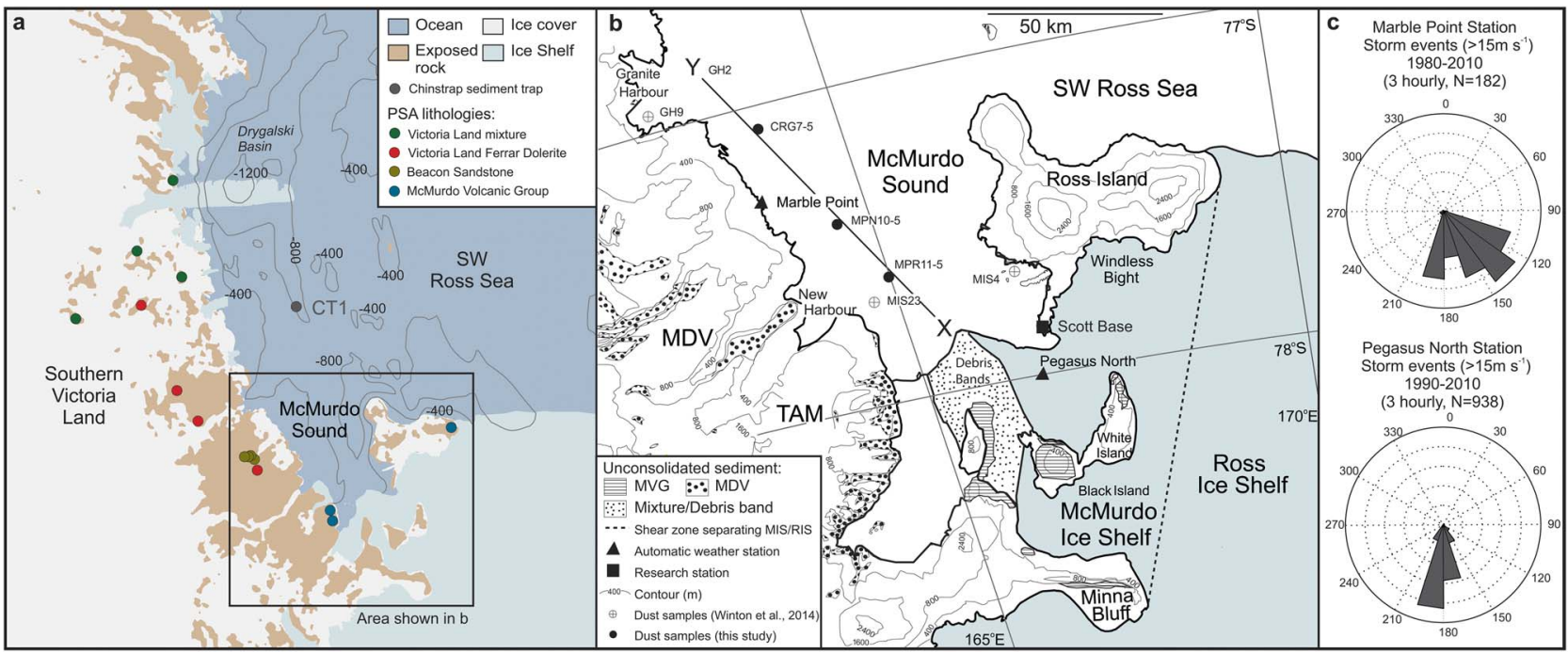

Fig. 1a. Map of the south-western (SW) Ross Sea showing the location of SW Ross Sea Chinstrap sediment trap (CT1). b. Insert of McMurdo Sound within the SW Ross Sea showing location of McMurdo Sound snow on sea ice samples (solid: this study, cross: Winton et al. (2014), shaded: exposed areas of unconsolidated sediment). Samples are named based on their location: MP = Marble Point, CR = Cape Robert, GH = Granite Harbour, MIS = McMurdo Sea Ice, MDV = McMurdo Dry Valleys, MIS = McMurdo Ice Shelf, MVG = McMurdo Volcanic Group, RIS = Ross Ice Shelf, TAM = Transantarctic Mountains. c. Wind roses illustrating the direction of storm events at Pegasus North and Marble Point automatic weather stations (AWS). Locations of AWS shown in Fig. 1b. Modified from Winton et al. (2014).

The largest expanse of contiguous ice-free ground in Antarctica is found in the McMurdo Dry Valleys, a series of west-to-east oriented, glacially carved valleys located between the high EAP and the Ross Sea in southern Victoria Land. However, the dustiest known place in Antarctica is located in the south-western (SW) Ross Sea, associated with the so-called 'debris bands' area on the McMurdo Ice Shelf (Kellogg et al. 1990) (Fig. 1). In this region, dust deposition flux $\left(\sim 1 \mathrm{~g} \mathrm{~m}^{-2} \mathrm{yr}^{-1}\right)$ is at least two orders of magnitude greater than fallout of long-range transported dust measured in ice cores from the EAP (Atkins \& Dunbar 2009, Delmonte et al. 2013, Chewings et al. 2014) and is, potentially, an important source of bioavailable Fe to the Ross Sea (Winton et al. 2014).

Dust provenance in Antarctica can be determined from the ${ }^{87} \mathrm{Sr} /{ }^{86} \mathrm{Sr}$ and ${ }^{143} \mathrm{Nd} /{ }^{144} \mathrm{Nd}$ radiogenic isotope composition of dust in snow and ice by comparison with potential source areas (PSAs) (e.g. Delmonte et al. 2010). This geochemical method allows mantle-derived (basaltic rocks, tephra and soils derived from them, weathered and eroded mafic rocks) and crustal-derived sediments and soils to be identified. Both the geochemical fingerprint and particle size of dust deposited on the EAP suggest it originates from arid regions in southern South America during glacial periods (Gaiero et al. 2007, Delmonte et al. 2008). However, for dust deposition during interglacial periods, that is when dust input to inner Antarctica was extremely low, the source is less certain (Delmonte et al. 2007), and an Australian contribution is probable
(Revel-Rolland et al. 2006, Delmonte et al. 2007, 2008). In addition to atmospheric circulation, dust transport efficiency is dependent on particle size; for example, long-range dust deposited on the EAP has a mass modal size of around $2 \mu \mathrm{m}$ (Delmonte et al. 2002). When investigating the provenance of dust, the fractionation of $\mathrm{Sr}$ isotopes into different grain size fractions needs to be considered, as there is a correlation between grain size and ${ }^{87} \mathrm{Rb} /{ }^{86} \mathrm{Sr}$ ratios, and thus ${ }^{87} \mathrm{Sr} /{ }^{86} \mathrm{Sr}$ ratios. In coarse (fine) grained suspended particulate matter, $\mathrm{Sr}$ is enriched (depleted) in less radiogenic $\mathrm{Sr}$ isotopic ratios (e.g. Andersson et al. 1994). In contrast, $\mathrm{Nd}$ isotopic ratios are not influenced to the same extent by particle size (e.g. Andersson et al. 1994).

\section{Iron fertilization in the Ross Sea}

The Ross Sea is one of the most productive regions in the Southern Ocean and an important oceanic sink for atmospheric carbon dioxide $\left(\mathrm{CO}_{2}\right)$ (e.g. Arrigo et al. 2008). The environmental factors responsible for controlling the rates of phytoplankton production and incomplete utilization of inorganic macronutrients include: grazing (Banse 1991), temperature (Bunt \& Wood 1963), light availability (e.g. Mitchell et al. 1991), micro-nutrient availability (e.g. Fe and Mn) (Sedwick \& DiTullio 1997, Sedwick et al. 2000), or a combination of these (e.g. Arrigo et al. 2000). Collier et al. (2000) show that a Ross Sea diatom productivity event, captured 
during the 1996-97 deployment of moored Antarctic Environment and Southern Ocean Process Study (AESOPS) sediment traps, is correlated with elevated lithogenic particle accumulation rates, excess $\mathrm{Fe}$ (determined from high $\mathrm{Fe} / \mathrm{Al}$ ratios), and with an early breakout of sea ice caused by katabatic winds. They go on to suggest that there may be a causal relationship between the retreat of sea ice, the supply of particulate $\mathrm{Fe}$, and diatom production and export. The source of this lithogenic $\mathrm{Fe}$ to the Ross Sea is unknown but could be derived from either dust released into the ocean from melting sea ice from local and/or from distal sources, or new particulate $\mathrm{Fe}$ derived from ice shelves, icebergs, upwelling of resuspended continental sediments from the sea floor, Circumpolar Deep Water or some combination thereof.

Multiple sources of new Fe to the Ross Sea region have been identified, which include local dust sourced mainly from the McMurdo Ice Shelf (Atkins \& Dunbar 2009, de Jong et al. 2013, Chewings et al. 2014, Winton et al. 2014), sea ice melt (Sedwick \& DiTullio 1997, de Jong et al. 2013), and lithogenic sediments resuspended from the sea floor (Sedwick et al. 2011, de Jong et al. 2013, Marsay et al. 2014, Gerringa et al. 2015). However, the relative importance of these sources for stimulating primary production remains an open question. Winton et al. (2014) estimate that the supply of soluble aeolian Fe in dust from the debris bands, southern McMurdo Sound to the adjacent ocean could support up to $~ 15 \%$ of primary production in the area. The implication being that $\mathrm{Fe}$ supporting the remaining $85 \%$ of productivity was derived largely from other sources, such as lithogenic sediment resuspended from the sea floor (Sedwick et al. 2011, de Jong et al. 2013, Marsay et al. 2014, Gerringa et al. 2015, Kustka et al. 2015, McGillicuddy et al. 2015).

As Fe is critical for seasonal phytoplankton growth in the Ross Sea, this study aimed to further investigate the source(s) of lithogenic Fe as a driver of the vast summer phytoplankton blooms in the SW Ross Sea by examining the provenance of lithogenic material sinking in the upper $200 \mathrm{~m}$ below sea level (m.b.s.l.) of the water column, and comparing its origin to both known local and global sources. This paper reports the $\mathrm{Sr}-\mathrm{Nd}$ isotopic composition of i) size-selected dust from snow samples on sea ice from McMurdo Sound, and ii) sediment trap material from the Research on Ocean - Atmosphere Variability and Ecosystem Response in the Ross Sea (ROAVERRS) moorings programme (1996-98) that represents accumulation of sediment settling out of the water column. When investigating PSAs to Antarctica, previous studies have size-selected the PSA samples prior to $\mathrm{Sr}$ analysis to be comparable to that of the fine size range of dust deposited in Antarctica (Delmonte et al. 2008), and a similar approach is used here.

\section{Methods}

Samples used in this study for Nd and Sr isotopic ration and concentration analysis

Previous studies have focused on dust flux and particle size distribution patterns in McMurdo Sound (Atkins \& Dunbar 2009, Dunbar et al. 2009, Chewings et al. 2014). This study is based on the following samples:

- Samples of dust-laden snow collected from sea ice along a south-north $\mathrm{X}-\mathrm{Y}$ transect in McMurdo Sound, collected in November 2010 and described in Chewings et al. (2014) and Winton et al. (2014) (Fig. 1b).

- A Ross Sea sediment trap sample from 200 m.b.s.l., collected between 25 December 1997 and 3 January 1998 from the ROAVERRS programme Chinstrap site $\left(76^{\circ} 20.5^{\prime} \mathrm{S}, 165^{\circ} 1.78^{\prime} \mathrm{E}\right)$ in the SW Ross Sea. This site was anchored in $830 \mathrm{~m}$ water depth in the southern extension of the Drygalski Basin (Fig. 1a).

Sample processing - McMurdo Sound surface snow on sea ice samples

The samples analysed in this work were size-selected in order to be comparable to provenance measurements made of dust from ice core PSAs and with similar studies on dust in Antarctica (e.g. Delmonte et al. 2004, 2008, 2010). Both the bulk (all particle sizes) and fine $(<10 \mu \mathrm{m})$ fraction of McMurdo Sound dust were analysed to check for particle size induced bias in the isotopic fractionation of samples. The coarse fraction was removed from bulk samples by using a pre-washed $10 \mu \mathrm{m}$ SEFAR Nitex ${ }^{\circledR}$ open mesh while the fraction $0.4 \mu \mathrm{m}<\varnothing<10 \mu \mathrm{m}$ was collected on $0.4 \mu \mathrm{m}$ Isopore ${ }^{\mathrm{TM}}$ polycarbonate membranes. After filtration the membranes were put into pre-cleaned Corning $^{\circledR}$ tubes filled with $\sim 10 \mathrm{ml}$ of ultra-pure water, and micro-particles were removed from the filter by sonication. Samples were transported to the Department of Geosciences, Swedish Museum of Natural History, Sweden, where the liquid was evaporated in acid-cleaned $15 \mathrm{ml} \mathrm{Savillex}{ }^{\circledR}$ beakers. Dry dust samples, ranging between 0.1 and $1.2 \mathrm{mg}$, were weighed a minimum of five times to obtain a mean weight, which was used for subsequent calculations.

\section{Sample processing - sediment trap samples}

Isotopic analysis of bulk sediment revealed that the biogenic fraction of the sediment (up to $70 \%$ total mass estimated from AESOPS sediment trap data reported in Collier et al. (2000)) incorporated marine $\mathrm{Sr}$, and thus the isotopic signature could not be distinguished from that of 
Table I. Nd and Sr concentrations and isotopic composition of McMurdo Sound and Chinstrap sediment trap samples analysed in this study.

\begin{tabular}{|c|c|c|c|c|c|c|c|c|c|c|c|c|c|c|}
\hline$\overline{\text { Sample }}$ & Size $(\mu \mathrm{m})$ & Location & $\begin{array}{c}\text { Date } \\
\text { sampled }\end{array}$ & ${ }^{143} \mathrm{Nd} /{ }^{144} \mathrm{Nd}$ & $\begin{array}{l} \pm 2 \sigma m e a a^{a} \\
* 10^{6}\end{array}$ & $\varepsilon \mathrm{Nd}(0)^{\mathrm{b}}$ & $\pm 2 \sigma^{\mathrm{c}}$ & $\begin{array}{l}\mathrm{CNd} \\
(\mathrm{ppm})\end{array}$ & ${ }^{87} \mathrm{Sr} /{ }^{86} \mathrm{Sr}$ & $\begin{array}{l} \pm 2 \sigma \operatorname{mean}^{\mathrm{d}} \\
* 10^{6}\end{array}$ & $\begin{array}{l}{ }^{87} \mathrm{Sr} /{ }^{86} \mathrm{Sr} \\
\text { corrected }\end{array}$ & $\pm 2 \sigma^{\mathrm{f} *} * 10^{6}$ & $\begin{array}{c}\mathrm{CSr} \\
(\mathrm{ppm})\end{array}$ & Reference \\
\hline \multicolumn{15}{|l|}{ McMurdo Sound } \\
\hline MPR 11-5 & Bulk & $\begin{array}{c}77^{\circ} 35.44^{\prime} \mathrm{S} \\
164^{\circ} 31.36^{\prime} \mathrm{E}\end{array}$ & Nov 2011 & 0.512580 & 12 & -1.1 & 0.2 & 110 & 0.708158 & 6.0 & 0.708186 & 8 & 140 & This study \\
\hline MPR11-5 & $<10$ & $\begin{array}{c}77^{\circ} 35.44^{\prime} \mathrm{S} \\
164^{\circ} 31.36^{\prime} \mathrm{E}\end{array}$ & Nov 2011 & 0.512590 & 7 & -0.94 & 0.2 & 220 & 0.709119 & 5.3 & 0.709147 & 8 & 320 & This study \\
\hline CRG7-5 & Bulk & $\begin{array}{c}77^{\circ} 05.44 ' \mathrm{~S} \\
163^{\circ} 41.86^{\prime} \mathrm{E}\end{array}$ & Nov 2011 & 0.512633 & 11 & -0.10 & 0.3 & 38 & 0.707607 & 4.2 & 0.707635 & 8 & 510 & This study \\
\hline CRG7-5 & $<10$ & $\begin{array}{c}77^{\circ} 05.44^{\prime} \mathrm{S} \\
163^{\circ} 41.86^{\prime} \mathrm{E}\end{array}$ & Nov 2011 & 0.512632 & 8 & -0.12 & 0.3 & 68 & 0.708943 & 8.0 & 0.708971 & 8 & 570 & This study \\
\hline MPN10-5 & Bulk & $\begin{array}{l}77^{\circ} 24.52^{\prime} \mathrm{S} \\
164^{\circ} 18.60^{\prime} \mathrm{E}\end{array}$ & Nov 2011 & 0.512735 & 6 & 1.9 & 0.4 & 40 & 0.706705 & 13 & 0.706733 & 13 & 6600 & This study \\
\hline MPN10-5 & $<10$ & $\begin{array}{c}77^{\circ} 24.52^{\prime} \mathrm{S} \\
164^{\circ} 18.60^{\prime} \mathrm{E}\end{array}$ & Nov 2011 & 0.512682 & 8 & 0.86 & 0.4 & 20 & 0.708188 & 6.4 & 0.708216 & 8 & 910 & This study \\
\hline GH2 & Bulk & $\begin{array}{l}76^{\circ} 55.33^{\prime} \mathrm{S} \\
163^{\circ} 6.17^{\prime} \mathrm{E}\end{array}$ & Nov 2009 & 0.512650 & 11 & 0.23 & 0.3 & 76 & 0.707299 & 12 & 0.707327 & 12 & 890 & This study \\
\hline GH2 & $<10$ & $\begin{array}{l}76^{\circ} 55.33^{\prime} \mathrm{S} \\
163^{\circ} 6.17^{\prime} \mathrm{E}\end{array}$ & Nov 2009 & 0.512654 & 6 & 0.31 & 0.3 & 72 & 0.708045 & 5.8 & 0.708073 & 8 & 620 & This study \\
\hline GH9 & Bulk & $\begin{array}{c}76^{\circ} 58.36^{\prime} \mathrm{S} \\
162^{\circ} 52.80^{\prime} \mathrm{E}\end{array}$ & Nov 2009 & 0.512321 & 5 & -6.18 & 0.3 & 37 & 0.712260 & 5.0 & 0.712288 & 8 & 290 & (Winton et al. 2014) \\
\hline MIS4 & Bulk & $\begin{array}{c}77^{\circ} 40.03^{\prime} \mathrm{S} \\
166^{\circ} 35.97^{\prime} \mathrm{E}\end{array}$ & Nov 2009 & 0.512815 & 4 & 3.45 & 0.3 & 56 & 0.705303 & 5.0 & 0.705331 & 8 & 800 & (Winton et al. 2014) \\
\hline MIS23 & Bulk & $\begin{array}{c}77^{\circ} 40.03^{\prime} \mathrm{S} \\
164^{\circ} 35.79^{\prime} \mathrm{E}\end{array}$ & Nov 2009 & 0.51276 & 6 & 2.38 & 0.3 & 51 & 0.705608 & 5.0 & 0.705636 & 8 & 520 & (Winton et al. 2014) \\
\hline $\begin{array}{l}\text { Ross Sea sediment } \\
\text { CT1 }\end{array}$ & Bulk & $\begin{array}{c}76^{\circ} 20.5^{\prime} \mathrm{S} \\
165^{\circ} 1.78^{\prime} \mathrm{E}\end{array}$ & 1997 & 0.512715 & 7 & 1.5 & 0.3 & 0.4 & 0.709008 & 5.1 & 0.709036 & 8 & 110 & This study \\
\hline CT1-leach & Bulk & $\begin{array}{c}76^{\circ} 20.5^{\prime} \mathrm{S} \\
165^{\circ} 1.78^{\prime} \mathrm{E}\end{array}$ & 1997 & 0.512836 & 8 & 3.9 & 0.3 & 0.5 & 0.704314 & 4.4 & 0.704342 & 8 & 20 & This study \\
\hline
\end{tabular}

${ }^{a}$ Internal precision, 2 standard errors of the mean.

${ }^{\mathrm{b}} \mathrm{Nd}$ isotopic ratios expressed as epsilon units $\varepsilon_{\mathrm{Nd}}(0)=\left[\left({ }^{143} \mathrm{Nd} /{ }^{144} \mathrm{Nd}\right)_{\text {sample }} /\left({ }^{143} \mathrm{Nd} /{ }^{144} \mathrm{Nd}\right)_{\mathrm{CHUR}}-1\right] \times 10^{4} ;$ CHUR $=$ chondritic uniform reservoir.

${ }^{\mathrm{c}}$ Uncertainty estimates based upon external precision for standard runs. Internal precision is used if it exceeds the external.

${ }^{\mathrm{d}}$ Internal precision, 2 standard errors of the mean.

${ }^{\mathrm{e}}$ Corrected to a NBS $987{ }^{87} \mathrm{Sr} /{ }^{86} \mathrm{Sr}$ ratio of 0.710245 .

${ }^{\mathrm{f}}$ Uncertainty estimates based upon external precision for standard runs. Internal precision is used if it exceeds the external. 


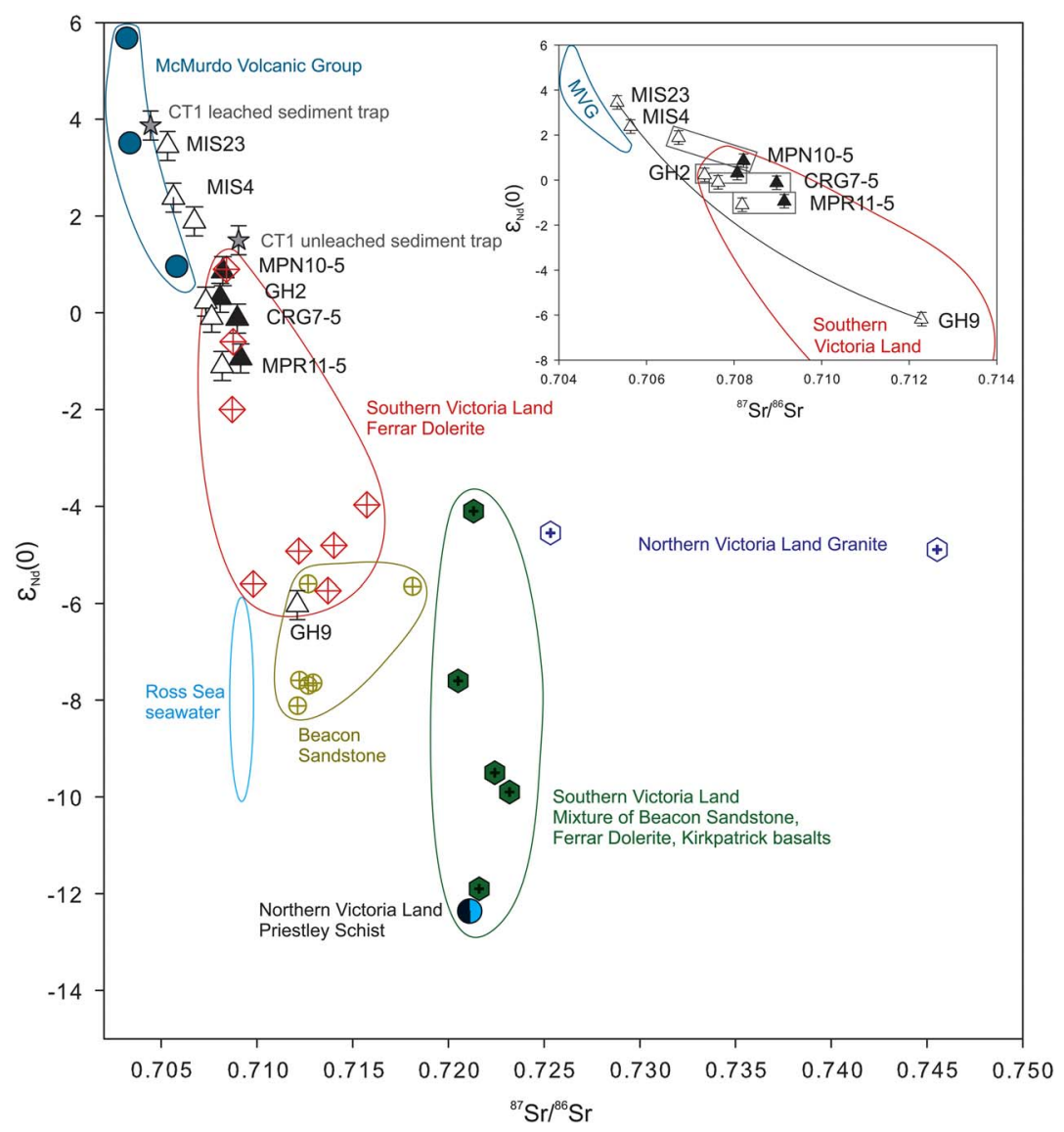

Fig. 2. Nd and Sr isotope signature of fine (black triangles) and bulk (white triangles) McMurdo Sound dust, including bulk McMurdo Sound data (GH9, MIS4 and MIS23; Winton et al. 2014), and leached and unleached Chinstrap sediment trap material. Data from southern Victoria Land potential dust sources that include different parent lithologies shown in Fig. 1 (Delmonte et al. 2004, 2010, 2013) and the isotopic composition of Ross Sea seawater (Elderfield 1986, Basak et al. 2015) are also plotted. Insert top right: McMurdo Sound dust highlighting the fractionation between fine and coarse particle sizes and a hypothetical mixing line between the two end members McMurdo Volcanic Group and southern Victoria Land, Transantarctic Mountains.

seawater (Table I). To remove the biogenic silica and calcium carbonate fraction, the sediment was leached with $6 \mathrm{M} \mathrm{HCl}$ in Savillex ${ }^{\circledR}$ beakers and centrifuged following the method of Freydier et al. (2001). The lithogenic residue was then rinsed three times with ultra-pure water and dried.

\section{Sample digestion}

The chemical treatment of the dust samples and leached sediment, including digestion and elemental separation $(\mathrm{Rb}-\mathrm{Sr}$ and $\mathrm{Sm}-\mathrm{Nd}$ ) using ion exchange chromatography, was performed at the Swedish Museum of Natural History following the established method of Delmonte et al. (2008). The samples were spiked with a mixed ${ }^{147} \mathrm{Sm} /{ }^{150} \mathrm{Nd}$ spike and ${ }^{84} \mathrm{Sr}$-enriched spike for the isotope dilution determination of the concentrations. Samples were digested in an acid mixture of $1.5 \mathrm{ml}$ of $\mathrm{HNO}_{3}, \mathrm{HF}$ and $\mathrm{HClO}_{4}$ heated to $90^{\circ} \mathrm{C}$ in closed Savillex ${ }^{\circledR}$ beakers for $24 \mathrm{~h}$.
The solution was evaporated to complete dryness on a hot plate and the residue re-dissolved in $4 \mathrm{ml} 6 \mathrm{M} \mathrm{HCl}$.

\section{Ion exchange}

To achieve separation of potential interfering elements ( $\mathrm{Fe}, \mathrm{Ba}, \mathrm{Rb}, \mathrm{Sm}, \mathrm{Ce}$ and $\mathrm{Pr}$ ), and obtain high column yield and low blanks, the residue was subjected to chemical procedures described in Delmonte et al. (2008). The total blank, including dissolution, chemical separation and mass spectrometry, was frequently monitored in each ion exchange batch and blank concentrations were $<5 \mathrm{pg}$ for $\mathrm{Nd}$ and $<130 \mathrm{pg}$ for $\mathrm{Sr}$.

\section{Mass spectrometry}

Isotopic analysis of $\mathrm{Nd}$ and $\mathrm{Sr}$ was performed with a Thermo Scientific TRITON Thermal Ionisation Mass 
Spectrometer. Neodymium was loaded mixed with colloidal graphite, Alfa Aesar, on double rhenium filaments and analysed as metal ions in static mode using rotating gain compensation. Concentrations and ratios were calculated assuming exponential fractionation. The calculated ratios were normalized to ${ }^{146} \mathrm{Nd} /{ }^{144} \mathrm{Nd}=0.7219$. Epsilon units are calculated as follows:

$\varepsilon_{\mathrm{Nd}}(0)=\left[\left({ }^{143} \mathrm{Nd} /{ }^{144} \mathrm{Nd}\right)_{\text {sample }} /\left({ }^{143} \mathrm{Nd} /{ }^{144} \mathrm{Nd}\right)_{\mathrm{CHUR}}{ }^{-1}\right] \times 10^{4}$,

where CHUR is the chondritic uniform reservoir with $\left({ }^{143} \mathrm{Nd} /{ }^{144} \mathrm{Nd}\right)_{\text {CHUR }}=0.512638$.

The external precision for ${ }^{143} \mathrm{Nd} /{ }^{144} \mathrm{Nd}$ is estimated from analysis of the $\mathrm{nNd} \beta$ standard (Wasserburg et al. 1981) by analysing a range, 4-12 ng loads, of $\mathrm{nNd} \beta$ standard. The external precision becomes larger for smaller loads, with an estimated precision of $\sim 40 \mathrm{ppm}$ for small loads, $\sim 30 \mathrm{ppm}$ for intermediate loads and $\sim 20$ ppm for larger loads. These values have been used to estimate the errors for the samples shown in Table I. The mean ${ }^{143} \mathrm{Nd} /{ }^{144} \mathrm{Nd}$ ratio for the $\mathrm{nNd} \beta$ was $0.511895 \pm 22$ $(n=20)$. Literature values for repeated analysis of standard $\mathrm{nNd} \beta$ (Andreasen \& Sharma 2006) yielded ${ }^{143} \mathrm{Nd} /{ }^{144} \mathrm{Nd}=0.511892 \pm 3(2 \sigma, n=23)$, and thus no accuracy correction was applied.

Purified Sr samples were mixed with tantalum activator and loaded on a single rhenium filament. Two hundred $8 \mathrm{~s}$ integrations were recorded in multi-collector static mode, applying a rotating gain compensation. Measured ${ }^{87} \mathrm{Sr}$ intensities were corrected for $\mathrm{Rb}$ interference assuming ${ }^{87} \mathrm{Rb} /{ }^{85} \mathrm{Rb}=0.38600$, and ratios were calculated using the exponential fractionation law and ${ }^{88} \mathrm{Sr} /{ }^{86} \mathrm{Sr}=8.375209$. External precision for ${ }^{87} \mathrm{Sr} /{ }^{86} \mathrm{Sr}$, estimated from analysing NBS SRM987 standard, was calculated as $\pm 0.000016(n=12)$, while repeated measurements of prepared CIT \#39 seawater gave a reproducibility of \pm 0.0000082 or $12 \mathrm{ppm}(n=21)$ which was taken to be the best estimate of the external precision. Accuracy correction was applied to the ${ }^{87} \mathrm{Sr} /{ }^{86} \mathrm{Sr}$ ratios corresponding to a ${ }^{87} \mathrm{Sr} /{ }^{86} \mathrm{Sr}$ ratio of 0.710245 for NBS SRM 987 standard (NBS 987: literature value 0.710245, Department of Geosciences value $0.710217 \pm 16(n=12)$; difference: 0.000028 ).

The accuracy of the $\mathrm{Nd}$ and $\mathrm{Sr}$ isotopic composition of small dust samples was determined using the Basalt Columbia River rock standard (BCR-2), a certified reference material. Preparation and analysis of $150-600 \mu \mathrm{g}$ aliquots of BCR-2 in each batch of ion exchange resulted in a recovery of $>79 \% \quad(n=6)$ for concentration and $>99 \% \quad(n=6)$ for isotopic composition. Due to the small dust samples and the difficulty of weighing such small masses an $\mathrm{Sr}$ and $\mathrm{Nd}$ concentration error of $\pm 10 \%$ was estimated by repeated weighing of BCR-2 standards ( $0.3 \mathrm{mg})$.

\section{Results}

The $\mathrm{Sr}$ and $\mathrm{Nd}$ isotopic composition of dust are primarily related to lithology and geologic age of parent materials, although the $\mathrm{Sr}$ isotopic composition, for particles between $2-50 \mu \mathrm{m}$, can also be influenced by size. The $\mathrm{Sr}$ and $\mathrm{Nd}$ isotopic composition of the fine $(<10 \mu \mathrm{m})$ and bulk (all sizes included) dust samples collected in this study are well characterized and reported in Table I and Fig. 2 along with additional isotopic data from McMurdo Sound measured in an earlier study (Winton et al. 2014). Samples in Fig. 2 are grouped by geographical location. The samples collected from the snow on sea ice in McMurdo Sound display a narrow isotopic composition $\left(0.70533<{ }^{87} \mathrm{Sr} /{ }^{86} \mathrm{Sr}<0.70915\right.$ and $\left.-1.1<\varepsilon_{\mathrm{Nd}}(0)<3.45\right)$. Our fine dust $(<10 \mu \mathrm{m})$ samples have relatively higher ${ }^{87} \mathrm{Sr} /{ }^{86} \mathrm{Sr}$ ratios compared to the bulk samples (Fig. 2), consistent with previous studies of size-dependent fractionation (Andersson et al. 1994). The Nd isotopes do not fractionate with the particle size (with the exception of MPN10-5 which could be related to the different size fractions originating from different sources; Fig. 2), also consistent with previous studies. The $\Delta^{87} \mathrm{Sr} /{ }^{86} \mathrm{Sr}$ is $\sim 0.00115$, that is slightly smaller than the ${ }^{87} \mathrm{Sr} /{ }^{86} \mathrm{Sr}$ increase of $\sim 0.0028$ units observed between $63 \mu \mathrm{m}$ and $2 \mu \mathrm{m}$ dust particles by Gaiero et al. (2007). The isotopic ratios of leached (lithogenic sediment fraction) and unleached (lithogenic and biogenic sediment fraction) Ross Sea sediment obtained from the upper Chinstrap sediment trap ( 200 m.b.s.1.) are reported in Table I. Leaching had a significant effect on the $\mathrm{Sr}$ isotopic ratio of this sample and removed an $\mathrm{Sr}$ seawater overprint from the sediment. After leaching, the remaining lithogenic sediment has an isotopic signature between the McMurdo Volcanic Group (MVG) and southern Victoria Land PSAs (Fig. 2).

\section{Discussion}

\section{Dust provenance - McMurdo Sound}

The overwhelming majority of dust deposited in snow on sea ice in McMurdo Sound is locally sourced. It is not possible to detect any contribution from South American or Australian sources with our approach. Sedimentological, meteorological and geochemical evidence consistently points to the debris bands on the McMurdo Ice Shelf (Kellogg et al. 1990) as the dominant local dust source in the McMurdo Sound region (Fig. 1) (Atkins \& Dunbar 2009, Chewings et al. 2014, Winton et al. 2014). Studies of spatial variability of dust and 
particle size for the greater McMurdo Sound region show a distinct decrease in particle size and dust flux along transect $\mathrm{X}-\mathrm{Y}$ (Fig. 1b) as part of a dust plume extending northwards from the debris bands (Atkins \& Dunbar 2009, Chewings et al. 2014). As the plume extends northwards away from the debris bands the particle size and dust accumulation rate decrease, although secondary elevated patches of both occur near coastal headlands. Overall, dust accumulation declines exponentially from $55 \mathrm{~g} \mathrm{~m}^{-2} \mathrm{yr}^{-1}$ near the debris bands to $\sim 0.2 \mathrm{~g} \mathrm{~m}^{-2} \mathrm{yr}^{-1}$ $120 \mathrm{~km}$ north of the debris bands (Atkins \& Dunbar 2009, Chewings et al. 2014). This northward dust dispersal is consistent with the local meteorology whereby the highest wind speeds, i.e. those most competent with respect to entraining silt and fine sand, are predominately from the south (Fig. 1c), dispersing dust from the debris bands north along the southern Victoria Land coastline.

In addition to sedimentological considerations, geochemical evidence also points to dust being locally sourced. The $\mathrm{Sr}$ isotopic composition of modern seawater is homogenous $\left({ }^{87} \mathrm{Sr} /{ }^{86} \mathrm{Sr}=0.70924\right.$; Elderfield 1986), and has a similar $\mathrm{Sr}$ isotopic composition to the geology in McMurdo Sound (Fig. 2). However, the Nd isotopic composition of the local geology and Ross Sea seawater $\left(-10<\varepsilon_{\mathrm{Nd}}(0)<-6\right.$; Basak et al. 2015) is distinguished in Fig. 2, and combined with other provenance indicators (coarse particle size, high dust flux and $\mathrm{Fe} / \mathrm{Al}$ elemental ratios; Atkins \& Dunbar 2009, de Jong et al. 2013) allows tracing of dust to local PSAs. Winton et al. (2014) report two $\mathrm{Sr}$ and $\mathrm{Nd}$ isotopic ratios of the bulk sediment from snow on sea ice in southern McMurdo Sound and one from Granite Harbour (Fig. 1). The values are consistent with dust originating from MVG, although within the Granite Harbour embayment there is also evidence for dust derived from TAM lithologies. The possibility that the volcanic signature of McMurdo Sound dust on sea ice is derived from volcanic rocks in Marie Byrd Land can be ruled out $\left(0.7026<{ }^{87} \mathrm{Sr} /{ }^{86} \mathrm{Sr}<0.7032\right.$ and $1.99<\varepsilon_{\mathrm{Nd}}(0)<6.87$ ) (Futa \& LeMasurier 1983, Hole \& LeMasurier 1994) due to the northerly direction of the prevailing winds (Chewings et al. 2014).

Consequently, only local PSAs are considered for comparison to the new isotopic dataset. Overall, the $\mathrm{Sr}$ isotopic ratios for McMurdo Sound samples analysed in this study, and in Winton et al. (2014), are tightly grouped and range between $0.705<{ }^{87} \mathrm{Sr} /{ }^{86} \mathrm{Sr}<0.709$ while $\varepsilon_{\mathrm{Nd}}(0)$ ranges between $3.45<\varepsilon_{\mathrm{Nd}}(0)<-1.1$. These new isotopic data form a linear array in Fig. 2. McMurdo Sound dust can be considered the result of a two-component mixture derived from isotopically distinct end-members: i) the MVG volcanic rocks and ii) southern Victoria Land lithologies found in the TAM, such as Ferrar Dolerites and sandstones of the Beacon Supergroup (Fig. 2). The narrow range of isotopic ratios of McMurdo Sound dust along the south-north transect $\mathrm{X}-\mathrm{Y}$ represents northwards dust dispersal downwind from the debris bands, that is a mixture of TAM and MVG sources, with minor localized additions of TAM dust input from coastal outcrops from New Harbour and Marble Point that contribute to the dominant south to north dust plume (Fig. 1). This is consistent with field observations showing sediment on the McMurdo Ice Shelf debris bands is itself a mixture of MVG and TAM lithologies (Kellogg et al. 1990).

Previous studies have shown dust deposited within embayments or adjacent to headlands along the south Victoria Land coastline is not widely dispersed (Barrett et al. 1983, de Jong et al. 2013, Chewings et al. 2014). Within the narrow range of isotopic ratios of McMurdo Sound dust, GH9 is isotopically distinct and displays a dominant TAM signature (Fig. 2). This sample is not situated under the main northward-directed dust plume and hence represents localized dust accumulation within the Granite Harbour embayment (Fig. 1). In contrast, the isotopic composition of $\mathrm{GH} 2$ lies within the tight cluster of McMurdo Sound dust and thus highlights that the mass of dust on the sea ice immediately seawards of Granite Harbour originates from the south. A single source from the debris bands is also consistent with $\mathrm{Fe}$ concentrations within dust samples that were uniform along the transport pathway (Winton et al. 2014).

\section{Dust provenance - south-western Ross Sea}

The isotopic signature of the lithogenic fraction of sediment from the upper 200 m.b.s.l. Chinstrap sediment trap, located $\sim 170 \mathrm{~km}$ north of the debris bands $\left({ }^{87} \mathrm{Sr} /{ }^{86} \mathrm{Sr}=0.704, \quad \varepsilon_{\mathrm{Nd}}(0)=3.9\right)$, falls outside of the isotopic range of dust originating in Australia $\left(0.709<{ }^{87} \mathrm{Sr} /{ }^{86} \mathrm{Sr}<0.763,-2.9<\varepsilon_{\mathrm{Nd}}(0)<-15.4\right.$; Delmonte et al. 2004, Revel-Rolland et al. 2006) and South America $\left(0.704<{ }^{87} \mathrm{Sr} /{ }^{86} \mathrm{Sr}<0.713,-8.9<\varepsilon_{\mathrm{Nd}}(0)<-8.3\right.$; Delmonte et al. 2004). These two potential Southern Hemisphere sources supply dust to the high elevation EAP at very low deposition rates (e.g. Delmonte et al. 2008). The signature of the lithogenic fraction of sediment from SW Ross Sea (Chinstrap) matches that of the local geology and dust on sea ice in McMurdo Sound. Thus, the lithogenic particles, and their associated Fe, collected here are 'locally' sourced from the Ross Sea region (Fig. 2).

\section{Dust transport and deposition - south-western Ross Sea}

Deposition of local dust into the SW Ross Sea can occur by direct atmospheric fallout into ice-free surface waters, and release into surface waters by sea ice melt associated with subsequent northwards advection (Atkins \& Dunbar 2009, de Jong et al. 2013, Chewings et al. 2014). The geographical area over which local dust is transported 


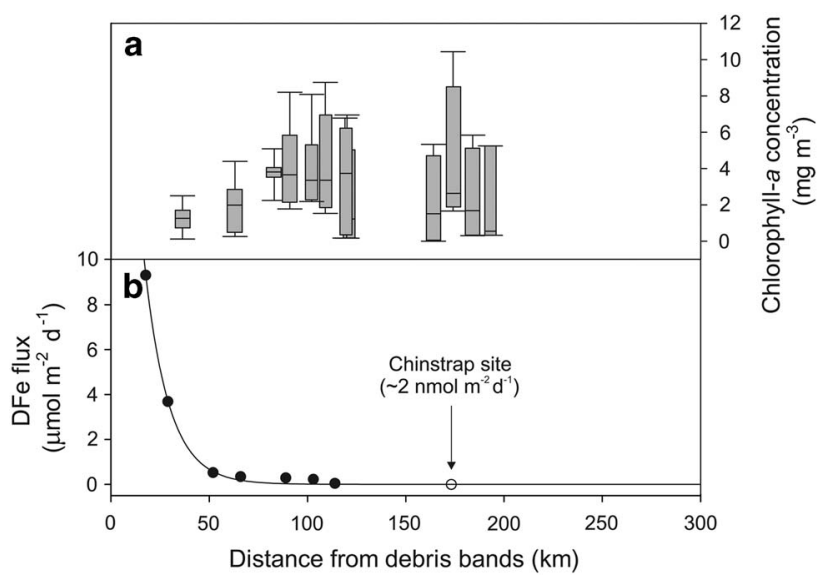

Fig. 3a. Rate of primary production with distance from McMurdo Sound. As the dust flux exponentially decreases, the rate of primary production increases. Primary production inferred from the annual mean chlorophyll $a$ concentration (2000-09) in the McMurdo Sound polynya $\left(72.0^{\circ} \mathrm{S}-78.083^{\circ} \mathrm{S}, 160.916^{\circ} \mathrm{E}-179.040^{\circ} \mathrm{W}\right)$ from SeaWiFS satellite data (http://giovanni.gsfc.nasa.gov). b.

Extrapolation of the annual DFe flux from McMurdo Sound into the south-western Ross Sea (DFe data sourced from Winton et al. (2014)). The predicted dust flux at the Chinstrap site is estimated at $\sim 0.01 \mathrm{~g} \mathrm{~m}^{-2} \mathrm{yr}^{-1}$ with a corresponding DFe flux of $\sim 2 \mathrm{nmol} \mathrm{m}^{-2} \mathrm{~d}^{-1}$.

into the Ross Sea, and hence contributes to Fe fertilization, is potentially large. Although dust accumulation measurements only exist up to $120 \mathrm{~km}$ from the debris bands and decrease exponentially from the source, local dust deposition probably extends far beyond this point. Extrapolating the dust flux trend observed by Chewings et al. (2014) suggests that the Chinstrap site may represent a northern extension of the dust and DFe dispersal pattern reported by Winton et al. (2014). The estimated annual accumulation rate from aeolian dust at the Chinstrap site is $\sim 0.01 \mathrm{~g} \mathrm{~m}^{-2} \mathrm{yr}^{-1}$, although we do not have accumulation rate data from the Chinstrap sediment trap with which to compare this estimate. Whether or not locally sourced aeolian sediment is the main source of the lithogenic sediment in the Chinstrap site remains somewhat of an open question. However, when the relationship between $\mathrm{DFe}$ and phytoplankton productivity in McMurdo Sound is considered we suggest this is unlikely to be the case (Fig. 3).

\section{Implications for iron fertilization}

By extrapolating the dust flux trend observed by Chewings et al. (2014) and its associated contribution to DFe (Winton et al. 2014) into the SW Ross Sea, the upper bound of the DFe at the Chinstrap site from the debris bands can be estimated (Fig. 3). Assuming a lithogenic dust flux of $\sim 0.01 \mathrm{~g} \mathrm{~m}^{-2} \mathrm{yr}^{-1}$ and an associated total $\mathrm{Fe}$ content of $4 \%$ and $11 \%$ of this $\mathrm{Fe}$ is soluble
(Winton et al. 2014), the maximum DFe flux is estimated to be $\sim 2 \mathrm{nmol} \mathrm{m} \mathrm{d}^{-1}$ to the Chinstrap site (Fig. 3). However, when this is considered relative to the spatial distribution of primary production in the SW Ross Sea, using averaged annual Sea-Viewing Wide Field-ofView Sensor (SeaWiFS) satellite chlorophyll $a$ data, the gradient in increasing chlorophyll $a$ concentration with distance from the debris bands within the McMurdo Sound polynya does not match the pattern of decreasing dust accumulation (Fig. 3). This pattern suggests that $\mathrm{DFe}$ from dust does not regulate growth in the SW Ross Sea. A seasonal phytoplankton bloom occurs in the McMurdo Sound polynya SW Ross Sea each summer and is dominated by diatoms. The rate of primary production is greatest in the centre of the McMurdo Sound polynya. As the dust flux decreases and primary production increases with distance from McMurdo Sound, it is difficult to reconcile these patterns at the Chinstrap site assuming only a local dust source (Fig. 3).

Some further insight into the origin of sediment in the water column in the SW Ross Sea may be inferred from the data published by Collier et al. (2000). They show a significantly elevated lithogenic accumulation rate in deep AESOPS sediment traps compared to accumulation rates measured in the upper AESOPS sediment traps at other sites in the Ross Sea (e.g. MS-7; $76^{\circ} 30^{\prime} \mathrm{S}, 178^{\circ} 1^{\prime} \mathrm{W}$ ). In addition, lithogenic Fe fluxes between $1-90 \mu \mathrm{g} \mathrm{m}^{-2} \mathrm{~d}^{-1}$ have been measured for the upper $200 \mathrm{~m}$.b.s.l. AESOPS trap (MIS-7b) and 40-850 $\mu \mathrm{g} \mathrm{m}^{-2} \mathrm{~d}^{-1}$ for the deep trap (MS-7a). The greater mass of sediment and lithogenic $\mathrm{Fe}$ flux in the deep traps in the Ross Sea highlight that concentrations of suspended sediment in the water column at these sites cannot simply result from sediment input at the surface (whereby the accumulation in each trap would be the same regardless of depth). Instead, the increase in accumulation with depth probably reflects resuspension and horizontal near-bottom transport processes. While we do not have the data to constrain these processes at Chinstrap we infer, based on the provenance of the lithogenic sediment and distance from known local sources, that the lithogenic sediment accumulating there is most probably dominated by resuspended bottom sediments, potentially from sills either side of the Drygalski Basin but also locally sourced material falling through the water column sourced from atmospheric deposition or ice rafting. Although no $\mathrm{Fe}$ flux data for the Chinstrap site are available, future work could examine the relationship between Fe fluxes in the Chinstrap sediment trap and those DFe fluxes reported for locally derived dust at McMurdo Sound.

Despite McMurdo Sound representing the upper bound of locally derived dust and associated DFe to Antarctic waters, previous studies have ruled out local dust as the major source of DFe supply for phytoplankton 
blooms in the Ross Sea. Dissolved Fe in McMurdo Sound dust can only support up to $15 \%$ of primary production in the region (Winton et al. 2014). Furthermore, based on regional scale estimates of dust deposition to the Southern Ocean, primary production triggered by long-range transported dust is likely to be less significant than local dust (e.g. Edwards \& Sedwick 2001). Evidence from the extrapolation of the mass accumulation rate to the upper 200 m.b.s.l. Chinstrap trap, the sedimentological study of Chewings et al. (2014), sedimentation in the water column, and the low contribution of local aeolian DFe to phytoplankton blooms, suggest that it is unlikely that aeolian dust deposition is the dominant process by which lithogenic Fe is supplied to the water column in the SW Ross Sea. Considered together, these lines of evidence point to a combination of resuspended bottom sediments with smaller additions of local dust sourced from atmospheric deposition or ice rafting as the sources of Fe-bearing sediment to the water column in the SW Ross Sea.

More broadly, Sedwick et al. (2011) noted that the phytoplankton-Fe limitation must be overcome by continuous replenishment from new sources to sustain the significant biomass observed over summer. They considered the following as potential sources of new DFe: vertical mixing, lateral advection, aerosol input and dissolution of particulate Fe from any or all of these sources. Consistent with upwelling of DFe as a major source of DFe in the Ross Sea, Marsay et al. (2014) reported high DFe concentrations within $50 \mathrm{~m}$ of the sea floor in the summer of 2012. Most recently, Gerringa et al. (2015) measured seawater DFe concentrations in the 2013-14 summer, and concluded that DFe from the sea floor and land mass sediments are the main sources of DFe which support phytoplankton in the upper mixed layer of the Ross Sea polynya in the early summer. Similarly, phytoplankton blooms in the Pennell Bank region of the Ross Sea are supported by upwelling of DFe (Kustka et al. 2015). However, Kustka et al. (2015) also highlight the spatial variability of processes supplying DFe in the Ross Sea. For example, circulation patterns around bathymetric features can alter the input of $\mathrm{DFe}$ from increased upwelling rates and higher concentrations of DFe. Numerical modelling of DFe supply by McGillicuddy et al. (2015) suggests that the largest sources to the euphotic zone are wintertime mixing and melting sea ice (e.g. Sedwick \& DiTullio 1997, de Jong et al. 2013) with smaller inputs from Circumpolar Deep Water and from melting glacial ice.

\section{Conclusions}

Dust extracted from surface snow on McMurdo Sound sea ice enables us to document the present day provenance of dust reaching the SW Ross Sea. Based on our measurements of $\mathrm{Sr}$ and $\mathrm{Nd}$ isotopic ratios of dust deposited in surface snow on sea ice at McMurdo Sound and in the Chinstrap sediment trap in the SW Ross Sea we conclude the following: i) The $\mathrm{Sr}$ and $\mathrm{Nd}$ isotopic signature of lithogenic sediment from the upper Chinstrap sediment trap in the SW Ross Sea $\left(\varepsilon_{\mathrm{Nd}}(0)=3.9\right.$, $\left.{ }^{87} \mathrm{Sr} /{ }^{86} \mathrm{Sr}=0.70434\right)$ matches local dust sources. ii) McMurdo Sound has been well characterized in terms of the $\mathrm{Sr}$ and $\mathrm{Nd}$ isotopic composition of locally derived dust deposited on sea ice. Dust found there displays a narrow isotopic field between $0.70533<{ }^{87} \mathrm{Sr} /{ }^{86} \mathrm{Sr}<0.70819$ and $-1.1<\varepsilon_{\mathrm{Nd}}(0)<3.45$ for the bulk fraction and $0.70807<{ }^{87} \mathrm{Sr} /{ }^{86} \mathrm{Sr}<0.70915$ and $-0.94<\varepsilon_{\mathrm{Nd}}(0)<0.86$ for the fine fraction. Due to Sr isotopic fractionation with particle size, the signature of the fine fraction adds to the PSA database for comparison to Antarctic ice core dust provenance studies. iii) Locally derived dust from McMurdo Sound is unlikely to be the major source of DFe for seasonal phytoplankton blooms in the SW Ross Sea. Although, Sr and Nd isotopic ratios of local dust on sea ice show similarities to lithogenic marine sediment, we acknowledge the limited transport distance of coarse-sized dust in this region. As dust transport varies from year to year, we cannot completely exclude the possibility that local dust can contribute to DFe to the greater Ross Sea region although this is not the dominant source of lithogenic Fe. iv) We surmise that there is significant remobilization and upwelling of Fe from the sea floor that contributes to Fe fertilization of phytoplankton during the summer in the SW Ross Sea. Finally, v) source information of dust inputs to regions, such as the Ross Sea, improves the ability to predict how such supply will change as the climate changes. As local sources are important to the SW Ross Sea, this data could be included in models that predict changes in snow and ice cover in the region.

\section{Acknowledgements}

We would like to thank Antarctica New Zealand and Scott Base personnel for logistics support. Thank you to Jane Chewings, Associate Professor Brent Alloway and Assistant Professor Ana Aguilar-Islas for the collection of McMurdo Sound and Granite Harbour dust samples. Additional thanks to Professor Robert Dunbar for Chinstrap sediment trap samples from the ROAVERRS mooring programme. V.H.L.W would like to thank Curtin University (Australian Postgraduate Award and Curtin Research Scholarship) and Antarctic Science (Antarctic Science Bursary) for scholarship and other funding support. This project was funded by Curtin University (Curtin Research Fellowship to R.E.: RES-SE-DAP-AW-47679-1), and New Zealand Ministry of Science and Innovation through contracts to Victoria 
University of Wellington (Contracts: VUW0704; RDF-VUW1103) and GNS Science (Contracts: 540GCT32; C05X1001). Isotopic analyses for provenance characterization were carried out at the Swedish Museum of Natural History and were supported by the Department of Geosciences, Swedish Museum of Natural History. Thank you to Karin Wallner and Hans Schöberg for technical support. The isotopic dataset for this paper is freely available from the Curtin University Research Data repository http://doi.org/ $10.4225 / 06 / 5643$ EBA1C8473. The chlorophyll $a$ data was obtained freely from the Sea-Viewing Wide Field-of-View Sensor (http://giovanni.gsfc.nasa.gov/). Additional thanks for the helpful comments and suggestions of Jeroen de Jong and an anonymous reviewer that aided in revision of this manuscript.

\section{Author contributions}

V.H.L.W, G.B.D, C.B.A and N.A.N.B designed the research; G.B.D and C.B.A collected the samples; V.H.L.W, B.D and P.S.A prepared the samples and analysed the data; V.H.L.W, G.B.D, C.B.A, B.D and P.S.A evaluated the data; all authors contributed to the interpretation of the data and the writing of the manuscript.

\section{References}

Albani, S., Delmonte, B., Maggi, V., Baroni, C., Petit, J.R., Stenni, B., Mazzola, C. \& Frezzotti, M. 2012. Interpreting last glacial to Holocene dust changes at Talos Dome (East Antarctica): implications for atmospheric variations from regional to hemispheric scales. Climate of the Past, 8, 741-750.

Andersson, P.S., Wasserburg, G.J., Ingri, J. \& Stordal, M.C. 1994. Strontium, dissolved and particulate loads in fresh and brackish waters: the Baltic Sea and Mississippi Delta. Earth and Planetary Science Letters, 124, 195-210.

Andreasen, R. \& Sharma, M. 2006. Solar nebula heterogeneity in p-process samarium and neodymium isotopes. Science, 314, 806-809.

Arrigo, K.R., Ditullio, G.R., Dunbar, R.B., Robinson, D.H., VanWoert, M., Worthen, D.L. \& Lizotte, M.P. 2000. Phytoplankton taxonomic variability in nutrient utilization and primary production in the Ross Sea. Journal of Geophysical Research - Oceans, 105, 8827-8846.

Arrigo, K.R., van Dijken, G. \& Long, M. 2008. Coastal Southern Ocean: a strong anthropogenic $\mathrm{CO}_{2}$ sink. Geophysical Research Letters, 35, 10.1029/2008GL035624.

Atkins, C.B. \& Dunbar, G.B. 2009. Aeolian sediment flux from sea ice into southern McMurdo Sound, Antarctica. Global and Planetary Change, 69, 133-141.

BANSE, K. 1991. Rates of phytoplankton cell division in the field and in iron enrichment experiments. Limnology and Oceanography, 36, 1886-1898.

Barrett, P., Pyne, A. \& Ward, B. 1983. Modern sedimentation in McMurdo Sound, Antarctica. In Oliver, R.L., JAMES, P.R. \& JAGO, J.B., eds. Antarctic earth science. New York, NY: Cambridge University Press, 550-554.
Basak, C., Pahnke, K., Frank, M., Lamy, F. \& Gersonde, R. 2015. Neodymium isotopic characterization of Ross Sea Bottom Water and its advection through the southern South Pacific. Earth and Planetary Science Letters, 419, 211-221.

Boyd, P.W., Mackie, D.S. \& Hunter, K.A. 2010. Aerosol iron deposition to the surface ocean - modes of iron supply and biological responses. Marine Chemistry, 120, 128-143.

BunT, J.S. \& Wood, E.J.F. 1963. Microbiology of Antarctic sea-ice: microalgae and Antarctic sea-ice. Nature, 199, 1254-1255.

Chewings, J.M., Atkins, C.B., Dunbar, G.B. \& Golledge, N.R. 2014. Aeolian sediment transport and deposition in a modern high latitude glacial marine environment. Sedimentology, 61, 1535-1557.

Collier, R., Dymond, J., Honjo, S., Manganini, S., Francois, R. \& Dunbar, R. 2000. The vertical flux of biogenic and lithogenic material in the Ross Sea: moored sediment trap observations 1996-1998. Deep Sea Research II - Topical Studies in Oceanography, 47, 3491-3520.

De Jong, J., Schoemann, V., MaricQ, N., Mattielli, N., Langhorne, P., Haskell, T. \& Tison, J.-L. 2013. Iron in land-fast sea ice of McMurdo Sound derived from sediment resuspension and wind-blown dust attributes to primary productivity in the Ross Sea, Antarctica. Marine Chemistry, 157, 2440.

Delmonte, B., Petit, J.R. \& Maggi, V. 2002. Glacial to Holocene implications of the new 27000-year dust record from the EPICA Dome C (East Antarctica) ice core. Climate Dynamics, 18, 647-660.

Delmonte, B., Robert Petit, J., Basile-Doelsch, I., Jagoutz, E. \& MAGGI, V. 2007. 6. Late quaternary interglacials in East Antarctica from ice-core dust records. Developments in Quaternary Sciences, 7, 53-73.

Delmonte, B., Andersson, P.S., Hansson, M., Schöberg, H., Petit, J.R., Basile-Doelsch, I. \& MagGi, V. 2008. Aeolian dust in East Antarctica (EPICA-Dome $\mathrm{C}$ and Vostok): provenance during glacial ages over the last 800 kyr. Geophysical Research Letters, 35, 10.1029/2008GL033382.

Delmonte, B., Basile-Doelsch, I., Petit, J.R., Maggi, V., Revel-Rolland, M., Michard, A., Jagoutz, E. \& Grousset, F. 2004. Comparing the Epica and Vostok dust records during the last 220,000 years: stratigraphical correlation and provenance in glacial periods. Earth-Science Reviews, 66, 63-87.

Delmonte, B., Baroni, C., Andersson, P., Narcisi, B., Salvatore, M.C., Petit, J.R., Scarchilli, C., Frezzotti, M., Albani, S. \& Maggi, V. 2013. Modern and Holocene aeolian dust variability from Talos Dome (northern Victoria Land) to the interior of the Antarctic ice sheet. Quaternary Science Reviews, 64, 76-89.

Delmonte, B., Baroni, C., Andersson, P.S., Schoberg, H., Hansson, M., Aciego, S., Petit, J.R., Albani, S., Mazzola, C., Maggi, V. \& Frezzotti, M. 2010. Aeolian dust in the Talos Dome ice core (East Antarctica, Pacific/Ross Sea sector): Victoria Land versus remote sources over the last two climate cycles. Journal of Quaternary Science, $25,1327-1337$.

Dunbar, G.B., Bertler, N.A.N. \& McKay, R.M. 2009. Sediment flux through the McMurdo Ice Shelf in Windless Bight, Antarctica. Global and Planetary Change, 69, 87-93.

Edwards, R. \& Sedwick, P. 2001. Iron in East Antarctic snow: implications for atmospheric iron deposition and algal production in Antarctic waters. Geophysical Research Letters, 28, 3907-3910.

Elderfield, H. 1986. Strontium isotope stratigraphy. Palaeogeography, Palaeoclimatology, Palaeoecology, 57, 71-90.

Freydier, R., Michard, A., De Lange, G. \& Thomson, J. 2001. Nd isotopic compositions of Eastern Mediterranean sediments: tracers of the Nile influence during sapropel S1 formation? Marine Geology, 177, 45-62.

Futa, K. \& LeMasurier, W.E. 1983. Nd and Sr isotopic studies on Cenozoic mafic lavas from West Antarctica: another source for continental alkali basalts. Contributions to Mineralogy and Petrology, 83, 38-44. 
Gaiero, D.M., Brunet, F., Probst, J.-L. \& Depetris, P.J. 2007. A uniform isotopic and chemical signature of dust exported from Patagonia: rock sources and occurrence in southern environments. Chemical Geology, 238, 107-120.

Gerringa, L.J.A., Laan, P., van Dijken, G.L., van Haren, H., De Batr, H.J.W., Arrigo, K.R. \& Alderkamp, A.C. 2015. Sources of iron in the Ross Sea polynya in early summer. Marine Chemistry, 177, 447-459.

Hole, M.J. \& LeMasurier, W.E. 1994. Tectonic controls on the geochemical composition of Cenozoic, mafic alkaline volcanic rocks from West Antarctica. Contributions to Mineralogy and Petrology, 117, 187-202.

Kellogg, T.B., Kellogg, D. \& Stuiver, M. 1990. Late Quaternary history of the southwestern Ross Sea: evidence from debris bands on the McMurdo Ice Shelf, Antarctica. Antarctic Research Series, 50, 25-56.

Kustka, A.B., Kohut, J.T., White, A.E., Lam, P.J., Milligan, A.J., Dinniman, M.S., Mack, S., Hunter, E., Hiscock, M.R., Smith JR, W.O. \& Measures, C.I. 2015. The roles of MCDW and deep water iron supply in sustaining a recurrent phytoplankton bloom on central Pennell Bank (Ross Sea). Deep-Sea Research I - Oceanographic Research Papers, 105, 171-185.

Marsay, C.M., Sedwick, P.N., Dinniman, M.S., Barrett, P.M., Mack, S.L. \& McGillicuddy, D.J. 2014. Estimating the benthic efflux of dissolved iron on the Ross Sea continental shelf. Geophysical Research Letters, 41, 7576-7583.

McGillicuddy, D.J., Sedwick, P.N., Dinniman, M.S., Arrigo, K.R., Bibby, T.S., Greenan, B.J.W., Hofmann, E.E., Klinck, J.M., Smith, W.O., Mack, S.L., Marsay, C.M., Sohst, B.M. \& van Dijken, G.L. 2015. Iron supply and demand in an Antarctic shelf ecosystem. Geophysical Research Letters, 42, 8088-8097.

Mitchell, B.G., Brody, E.A., HolmHansen, O., McClain, C. \& Bishop, J. 1991. Light limitation of phytoplankton biomass and macronutrient utilization in the Southern Ocean. Limnology and Oceanography, 36, 1662-1677.

Revel-Rolland, M., De Deckker, P., Delmonte, B., Hesse, P.P., Magee, J.W., Basile-Doelsch, I., Grousset, F. \& Bosch, D. 2006. Eastern Australia: a possible source of dust in East Antarctica interglacial ice. Earth and Planetary Science Letters, 249, 1-13.

Sedwick, P.N. \& DiTullio, G.R. 1997. Regulation of algal blooms in Antarctic shelf waters by the release of iron from melting sea ice. Geophysical Research Letters, 24, 2515-2518.

Sedwick, P.N., DiTullio, G.R. \& Mackey, D.J. 2000. Iron and manganese in the Ross Sea, Antarctica: seasonal iron limitation in Antarctic shelf waters. Journal of Geophysical Research - Oceans, 105, $11321-11336$.

Sedwick, P.N., Marsay, C.M., Sohst, B.M., Aguilar-Islas, A.M., Lohan, M.C., Long, M.C., Arrigo, K.R., Dunbar, R.B., Saito, M.A., Smith, W.O. \& DiTullio, G.R. 2011. Early season depletion of dissolved iron in the Ross Sea polynya: implications for iron dynamics on the Antarctic continental shelf. Journal of Geophysical Research Oceans, 116, 10.1029/2010JC006553.

Wagener, T., Guieu, C., Losno, R., Bonnet, S. \& Mahowald, N. 2008. Revisiting atmospheric dust export to the Southern Hemisphere ocean: biogeochemical implications. Global Biogeochemical Cycles, 22, 10.1029/2007GB002984.

Wasserburg, G.J., Jacousen, S.B., DePaolo, D.J., McCulloch, M.T. \& Wen, T. 1981. Precise determination of $\mathrm{Sm} / \mathrm{Nd}$ ratios, $\mathrm{Sm}$ and $\mathrm{Nd}$ isotopic abundances in standard solutions. Geochimica et Cosmochimica Acta, 45, 2311-2323.

Winton, V.H.L., Dunbar, G.B., Bertler, N.A.N., Millet, M.A., Delmonte, B., Atrins, C.B., Chewings, J.M. \& Andersson, P. 2014. The contribution of aeolian sand and dust to iron fertilization of phytoplankton blooms in southwestern Ross Sea, Antarctica. Global Biogeochemical Cycles, 28, 10.1002/2013GB004574. 